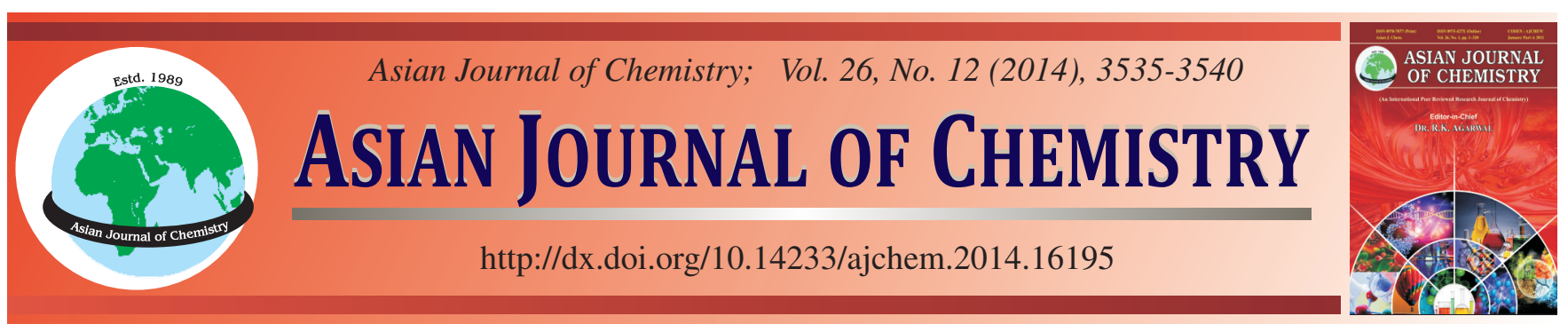

\title{
Magnetic Dispersion Extraction of Tetracyclines Residues from Milk by Chlortetracycline-Imprinted Magnetic Composite Microspheres
}

\author{
Na Li, Shu-Fang Lv, Yun-Kai Lv*, Xue Xiong and BaO-Hui Li
}

College of Chemistry and Environmental Science, Hebei University, Key Laboratory of Analytical Science and Technology of Hebei Province, Baoding 071002, P.R. China

*Corresponding author: Fax: +86 312 5079628; Tel: +86 312 5079359; E-mail: lvyunkai@hbu.edu.cn

A magnetic dispersion extraction method was developed based on a molecularly imprinted magnetic microsphere for fast separation and analysis of tetracyclines residues in milk samples. The molecularly imprinted magnetic microsphere was prepared by inverse emulsion suspension polymerization and synthesis and extraction conditions were optimized for obtaining excellent affinity and high selectivity. The magnetism, covering amount, clean-up of the magnetic microspheres were characterized by vibrating sample magnetometer, thermogravimetric analysis and HPLC. The molecularly imprinted magnetic microspheres were applied to separate tetracycline antibiotics from milk by magnetic dispersion extraction with a good sample clean-up effect. The average recoveries of four tetracycline antibiotics were obtained in the range of 76.4-95.84 \% with precision 2.72-6.81\%. The limits of detection and quantitation of the proposed method were in the range of 5.71-11.18 and 19.02-37.28 $\mu \mathrm{g} / \mathrm{kg}$, respectively. The results indicated that magnetic dispersion extraction of the molecularly imprinted magnetic microspheres was powerful for the food sample pretreatment with high selectivity and simplified procedure.

Keywords: Molecularly imprinted polymers, Magnetic microsphere, Magnetic dispersion extraction, Tetracyclines, Milk.

\section{INTRODUCTION}

A molecular imprinting magnetic separation technique had been developed based on magnetic molecularly imprinted polymers (MMIPs), which were firstly prepared by surfaceimprinting technique that the molecularly imprinted polymers (MIPs) were coated on the surface of the inorganic magnetic particle ${ }^{1}$. Compared with conventional solid-support substrates, magnetic particles have been proved to be efficient and promising materials. The MMIPs not only improve mass transfer and reduce permanent entrapment of the templates, but adsorbed analytes are easy to collect by an external magnetic field without additional centrifugation or filtration. Therefore, the development of the new MMIPs preparation methods has been the subject of active research due to a variety of applications in the biological and environmental samples.

Since the first magnetic molecular imprinted polymer beads have been prepared using suspension polymerization in perfluorocarbon ${ }^{1}$, several methods were developed for the preparation of molecularly imprinted magnetic microsphere (molecularly imprinted magnetic microsphere), including suspension polymerization $^{1-3}$, miniemulsion polymerization ${ }^{4}$, precipitation polymerization ${ }^{5}$, aqueous solution polymerization $^{6}$, reversible addition-fragmentation chain transfer $(\mathrm{RAFT})^{7}$, atom transfer radical polymerization $(\mathrm{ATRP})^{8}$ and silanization technique ${ }^{9}$. Among them, suspension polymerization is one of the most important microsphere synthesis methods. Although this technique produces uniform-sized microspheres in the supra-mm sized range, it is not suitable for high viscosity monomer and cross-linker because high viscosity affects the dispersion of monomer droplet and the formation of microspheres. An inverse emulsion suspension polymerization (IESP) can overcome the shortcomings of suspension polymerization and also improve the adsorption characteristics of the molecularly imprinted magnetic microspheres. The IESP includes three steps, namely preparation of inverse emulsion, pre-polymerization and suspension polymerization. This method would be able to solve the common problems existing in the suspension polymerization, such as the dispersion of high viscosity monomers, low porosity, microsphere adhesion and the inorganic magnetic particle leakage, which were resolved by pre-encapsulating the inorganic magnetic particles in inverse emulsion.

In this work, a molecularly imprinted magnetic microsphere was prepared by IESP using inverse emulsion of chlortetracycline (template), methacrylic acid, acrylamide, Span-80, 2,2-azobisisobutyronitrile, trimethylolpropane trimethacrylate and ferrofluid in hydroxyethyl cellulose aqueous solution. The microspheres were obtained and applied for the magnetic dispersion extraction of tetracyclines (TCs) from milk 
samples. As a result of their excellent property, the extraction and clean-up procedures were carried out in a single step which could greatly reduce or eliminate the sample matrix interferences.

\section{EXPERIMENTAL}

Tetracycline hydrochloride (TC), oxytetracycline hydrochloride (OTC), doxycycline hydrochloride (DC) and chlortetracycline hydrochloride (CTC) were purchased from Fluka (Buchs, Switzerland) and the stock solutions of antibiotics were prepared in water. Trimethylolpropane trimethacrylate (TRIM), methacrylic acid (MAA) and 4-vinylpyridine (4-VPY) were purchased from Tianjin Chemical Reagent Research Institute (Tianjin, China) and cleaned to remove the inhibitor prior to polymerization. Iron (II) chloride tetrahydrate $\left(\mathrm{FeCl}_{2} \cdot 4 \mathrm{H}_{2} \mathrm{O}\right)$, iron(III) chloride hexahydrate $\left(\mathrm{FeCl}_{3} \cdot 6 \mathrm{H}_{2} \mathrm{O}\right)$, acrylamide (AM), span-80, hydroxyethyl cellulose (HEC), polyvinyl alcohol (PVA) and 2,2-azobisisobutyronitrile (AIBN) were obtained from Beijing Chemical Reagent Company (Beijing, China) and 2,2-azobisisobutyronitrile was recrystallized from methanol before use. All the other chemicals were of the analytical or the HPLC grade and used without further disposal. Doubly deionized water was used throughout. Samples for HPLC were filtered through a $0.45 \mathrm{~mm}$ membrane filter. Citrate buffer $(0.1 \mathrm{~mol} / \mathrm{L}, \mathrm{pH} 4)$ was prepared by dissolving $21 \mathrm{~g}$ of ccitric acid monohydrate in less than $1 \mathrm{~L}$ of water, adjusting the $\mathrm{pH}$ with $\mathrm{NaOH}$ and diluting with water to $1 \mathrm{~L}$.

$\mathrm{Na}_{2}$ EDTA-McIlvaine buffer solution $(0.1 \mathrm{~mol} / \mathrm{L})$ was prepared by mixing $1000 \mathrm{~mL}$ of $0.1 \mathrm{~mol} / \mathrm{L}$ citric acid with $625 \mathrm{~mL}$ of $0.2 \mathrm{~mol} / \mathrm{L}$ disodium hydrogen phosphate $(\mathrm{pH}$ was adjusted to $4.0 \pm 0.05$ with $\mathrm{NaOH}$ or $\mathrm{HCl}$ as needed) and then $60.5 \mathrm{~g}$ of $\mathrm{Na}_{2}$ EDTA $2 \mathrm{H}_{2} \mathrm{O}$ was added into the above mixture ${ }^{10}$.

Instrumentation and analytical conditions: Sample analysis was performed using liquid chromatography system containing a LC-20AT pump and a SPD-20A UV-visible detector (Shimadzu, Japan). The analytes were separated on a Venusil XBP C18 column $(250 \times 4.6 \mathrm{~mm}, 5 \mathrm{~mm})$ from BonnaAgela Technologies (Tianjin, China). The mobile phase consisted of methanol/acetonitrile/ $10 \mathrm{mM}$ oxalic acid solution (5: $25: 70, \mathrm{v} / \mathrm{v})$. The flow rate of mobile phase was $1.0 \mathrm{~mL} / \mathrm{min}$ at $25{ }^{\circ} \mathrm{C}$ and the chromatograms were recorded at $355 \mathrm{~nm}$. The injection volume was $10 \mu \mathrm{L}$. The magnetic properties of the samples were measured at room temperature with vibrating sample magnetometer (VSM, Physcience Opoto-Electronice Co., Ltd., Beijing). The SEM micrographs of the microspheres were obtained by Hitachi TM3000 Tabletop Microscope (Tokyo, Japan).

Preparation of the molecularly imprinted magnetic microspheres: The synthesis of molecularly imprinted magnetic microsphere included four steps.

Preparation of $\mathrm{Fe}_{3} \mathrm{O}_{4}$ magnetite particles: The $\mathrm{Fe}_{3} \mathrm{O}_{4}$ magnetite particles with hydrophobic shell were prepared by a modified coprecipitation reaction. $\mathrm{FeCl}_{2} \cdot 4 \mathrm{H}_{2} \mathrm{O}(2.0 \mathrm{~g})$ and $\mathrm{FeCl}_{3} \cdot 6 \mathrm{H}_{2} \mathrm{O}(5.2 \mathrm{~g})$ were dissolved under $\mathrm{N}_{2}$ atmosphere in deaerated deionized water $(100 \mathrm{~mL})$ with vigorous mechanical stirring (800 rpm). A nitrogen gas environment was maintained in the vessel during the reaction to prevent critical oxidation. When the solution was preheated to $80^{\circ} \mathrm{C}$, a $40 \mathrm{~mL}$ of $\mathrm{NaOH}$ solution $(2.0 \mathrm{~mol} / \mathrm{L})$ was added dropwise into the mixture.
Then $2 \mathrm{~mL}$ of oleic acid was also added dropwise into the suspension. After $1 \mathrm{~h}$, the magnetic particles were isolated from the solvent by permanent magnet and washed several times with water $(100 \mathrm{~mL}$ each time) to remove unreacted chemicals until the stable particles were obtained.

Inverse polymerization emulsion: (a) Chlortetracycline hydrochloride $(0.515 \mathrm{~g}, 1 \mathrm{mmol})$, methacrylic acid $(0.9 \mathrm{~mL}$, $10 \mathrm{mmol})$, acrylamide $(0.36 \mathrm{~g}, 5 \mathrm{mmol})$ and water $(2 \mathrm{~mL})$ were added into a $50 \mathrm{~mL}$ beaker to obtain an aqueous solution. (b) Toluene $(5 \mathrm{~mL}), 2,2$-azobisisobutyronitrile $(0.1 \mathrm{~g})$ and Span-80 (0.3 g) were added into a $50 \mathrm{~mL}$ beaker, equipped with a reflux condenser, nitrogen inlet and stirrer. When Span80 was dispersed uniformly, (a) was added into it. The mixture was stirred vigorously and fully and the reaction system was purged with nitrogen for $0.5 \mathrm{~h}$. After homogeneity was achieved, the $\mathrm{Fe}_{3} \mathrm{O}_{4}$ magnetite $(1 \mathrm{~g}$ ) was added into the mixture and stirred for $10 \mathrm{~min}$. The inverse pre-polymerization emulsion (IPE) was obtained.

Preparation of inverse emulsion: 2,2-Azobisisobutyronitrile $(0.1 \mathrm{~g})$ and trimethylolpropane trimethacrylate $(10 \mathrm{~mL}$, $31 \mathrm{mmol}$ ) were added into a $50 \mathrm{~mL}$ beaker. When 2,2-azobisisobutyronitrile was dissolved completely, IPE was added into it. Ultrasonic dispersion was used to disperse the mixture and then inverse emulsion was obtained.

Suspension polymerization: Hydroxyethyl cellulose $(0.12 \mathrm{~g})$ was dissolved into $100 \mathrm{~mL}$ of water in a $250 \mathrm{~mL}$ threenecked round-bottom flask, which was equipped with a reflux condenser, nitrogen inlet and stirrer. And then the inverse emulsion was added. The reaction system was purged with nitrogen for $10 \mathrm{~min}$ prior to reach the reaction temperature. The reaction was allowed to proceed at $70{ }^{\circ} \mathrm{C}$ for $12 \mathrm{~h}$ and the stirrer speed was maintained at $400 \mathrm{rpm}$. When polymerization was finished, the product was cooled down to room temperature, filtered through a filter screen and washed three times with water, acetone, ethanol and water, respectively and then molecularly imprinted magnetic microspheres were obtained. A similar procedure without template was used to prepare the non-imprinted magnetic microsphere (NIM) as control material.

Rebinding experiment: The rebinding experiment was carried out by adding $50 \mathrm{mg}$ of the magnetic microspheres (molecularly imprinted magnetic microsphere or non-imprinted magnetic microsphere) in a $10 \mathrm{~mL}$ glass flask and a $5 \mathrm{~mL}$ of chlortetracycline hydrochloride solution (concentration varying from 0.05 to $0.5 \mathrm{mg} / \mathrm{mL}$ ) was added. All of the solutions were prepared in water. The flasks were properly sealed and the mixture was incubated under agitation in a horizontal shaker for $12 \mathrm{~h}$ at room temperature to facilitate the adsorption of chlortetracycline hydrochloride onto the magnetic particles and then the supernatant was separated and analyzed by UV. All tests were conducted in triplicate. The equilibrium adsorption capacity $(\mathrm{Q})$ was calculated according to eqn. (1): $\mathrm{Q}=\mathrm{V}$ $\left(\mathrm{C}_{0}-\mathrm{C}_{\mathrm{e}}\right) / \mathrm{m}$, where $\mathrm{V}$ is the volume of solution $(\mathrm{mL}) ; \mathrm{C}_{0}$ and $\mathrm{C}_{\mathrm{e}}$ are the initial and the equilibrium concentration of chlortetracycline hydrochloride in aqueous solution, respectively.

Magnetic dispersion extraction of tetracyclines from spiked milk samples: The magnetic dispersion extraction procedures were illustrated in Fig. 1. The milk samples were obtained from a local supermarket. $5 \mathrm{~g}$ of milk sample was 
added into a conical flask and $20 \mathrm{~mL}$ of $0.1 \mathrm{~mol} / \mathrm{L}$ citrate buffer ( $\mathrm{pH} 4.0)$ was also added. The mixture was homogenized for $2 \mathrm{~min} .50 \mathrm{mg}$ of the molecularly imprinted magnetic microspheres were put into other conical flask and conditioned in sequence with $3 \mathrm{~mL}$ of methanol and $3 \mathrm{~mL}$ of water. The molecularly imprinted magnetic microspheres were separated with a special magnetic rod and released to the above mixture. Then the mixture was stirred for $20 \mathrm{~min}$. Subsequently, the molecularly imprinted magnetic microspheres were transferred into a test tube and were washed with $2 \mathrm{~mL}$ of methanol-toluene $(1: 19 \mathrm{v} / \mathrm{v})$. Finally, the tetracyclines were eluted from the molecularly imprinted magnetic microspheres by $2 \mathrm{~mL}$ of $0.5 \%$ acetic acid methanol solution. The extract was combined and evaporated to dryness under nitrogen gas at $40{ }^{\circ} \mathrm{C}$ and the residue was reconstituted with $1 \mathrm{~mL}$ of mobile phase for further HPLC analysis. The spiked milk samples were prepared by spiked with tetracycline antibiotics at three concentration levels of $0.1,0.2,0.5 \mathrm{mg} / \mathrm{kg}$ and experiments were repeated three times (Fig. 1).
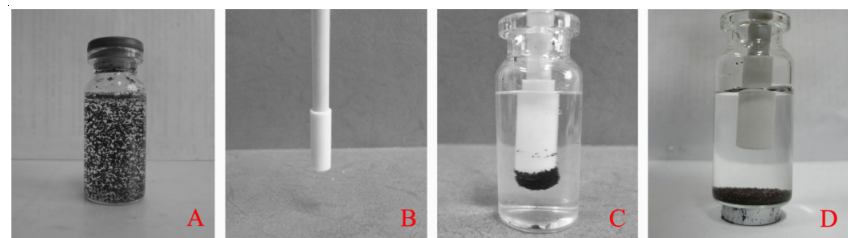

Fig. 1. Photographs of magnetic dispersion extraction process. (A) The MIMMs was suspended in water. (B) The special magnetic rod. (C) Separation of the MIMMs by the special magnetic rod. (D) Redispersion of the MIMMs by an external high magnetic field

\section{RESULTS AND DISCUSSION}

Optimization of preparation conditions: The kind of monomers had an obvious effect on molecular recognition selectivity of MIPs, because it directly related to complex formation between monomers and template molecules in the imprinting system ${ }^{11}$. In this study, the acidic (methacrylic acid), neutral (acrylamide) and basic (4-VPY) functional monomers were investigated. The methacrylic acid and acrylamide were chosen as the functional monomer and the molecularly imprinted magnetic microsphere showed specific recognition ability to the template chlortetracycline hydrochloride and the static equilibrium adsorption was $12.1 \mathrm{mg} / \mathrm{g}$.

It is well known that the dispersing agent influences the formation of uniform microspheres. Initially, it was attempted to produce microspheres by IESP using PVA as the dispersing agent. The photographs of the molecularly imprinted magnetic microspheres were shown in Fig. 2b, the microspheres were irregular and the distribution of the molecularly imprinted magnetic microspheres was wide. Thus, we used HEC as dispersing agent for increasing dispersion of trimethylolpropane trimethacrylate droplet. The microspheres were obtained (Fig. 2a), so HEC (0.12 g) was as dispersing agent. A $400 \mathrm{rpm}$ was used for stirring rate in the experiment.

Characterization of the molecularly imprinted magnetic microspheres: The magnetic property of the materials was tested at room temperature with vibrating sample magnetometer ${ }^{11}$. The similar hysteresis loops were observed for $\mathrm{Fe}_{3} \mathrm{O}_{4}$

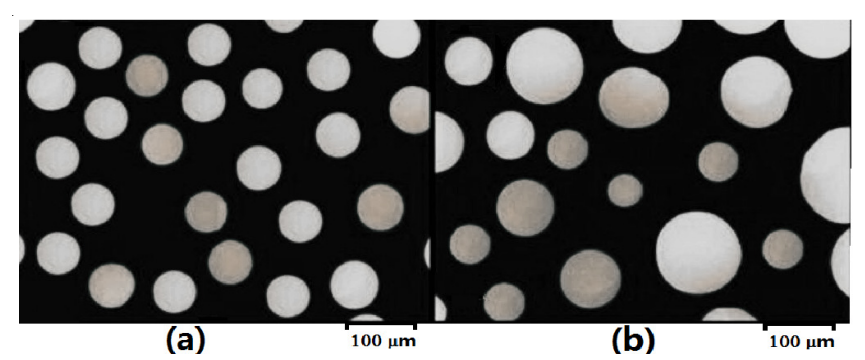

Fig. 2. Scanning electron microscope (SEM) images of the MIMMs

nanoparticles before and after encapsulation. The calculated saturation magnetization was $27.05 \mathrm{emu} / \mathrm{g}$ and $5.2 \mathrm{emu} / \mathrm{g}$ for the $\mathrm{Fe}_{3} \mathrm{O}_{4}$ particles and the molecularly imprinted magnetic microspheres, respectively. The result shown that no reduced remanence and coercivity being zero were detected, which indicated that $\mathrm{Fe}_{3} \mathrm{O}_{4}$ particles and molecularly imprinted magnetic microspheres are super paramagnetic. The magnetisms of the molecularly imprinted magnetic microspheres were displayed in Fig. 1. It was observed that the molecularly imprinted magnetic microspheres could be easily separated from the aqueous solution within few seconds by placing a permanent magnet near the glass bottle and the supernatant was colourless.

The magnetite content of the magnetic composite microspheres is evaluated by the thermogravimetric analysis system. Magnetic particles and molecularly imprinted magnetic microspheres were analyzed. As can be seen in Fig. 3, some weight was lost between room temperature and $600{ }^{\circ} \mathrm{C}$ in curve one, the magnetic particles and molecularly imprinted magnetic microspheres started degrading at about $220{ }^{\circ} \mathrm{C}$. The lost weight of the magnetic microspheres was $80 \%$ from 200 to $800{ }^{\circ} \mathrm{C}$ and the lost weight of the magnetic particles was $4 \%$ from 200 to $400{ }^{\circ} \mathrm{C}$. The result indicated that the magnetite content of the molecularly imprinted magnetic microspheres was $20 \%$.

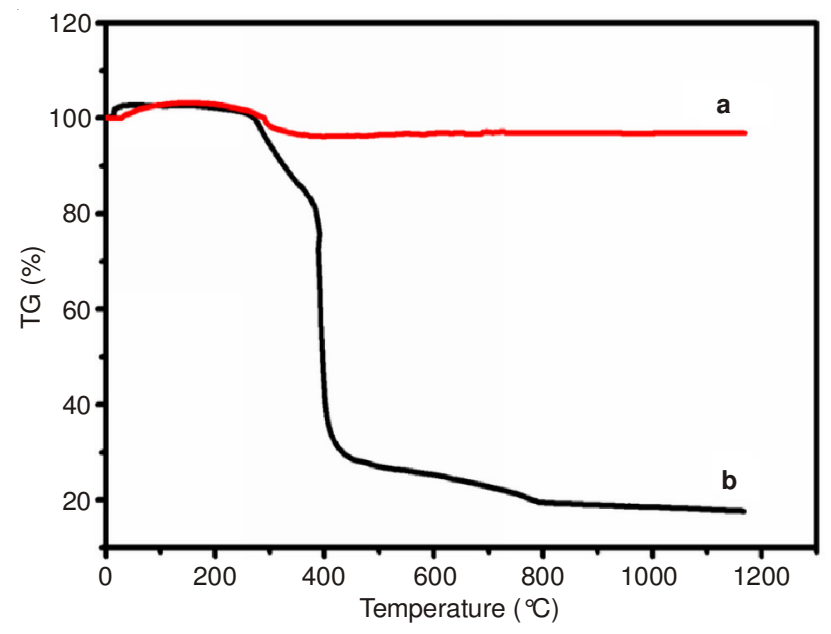

Fig. 3. TGA curves of magnetite particles (a) and the MIMM (b)

Rebinding study and scatchard analysis: The rebinding study was performed by subjecting the molecularly imprinted magnetic microspheres or non-imprinted magnetic microspheres to various initial concentrations of chlortetracycline hydrochloride (from 0.05 to $0.5 \mathrm{mg} \mathrm{mL}^{-1}$ ) by magnetic dispersion extraction. The binding isotherms of chlortetracycline 

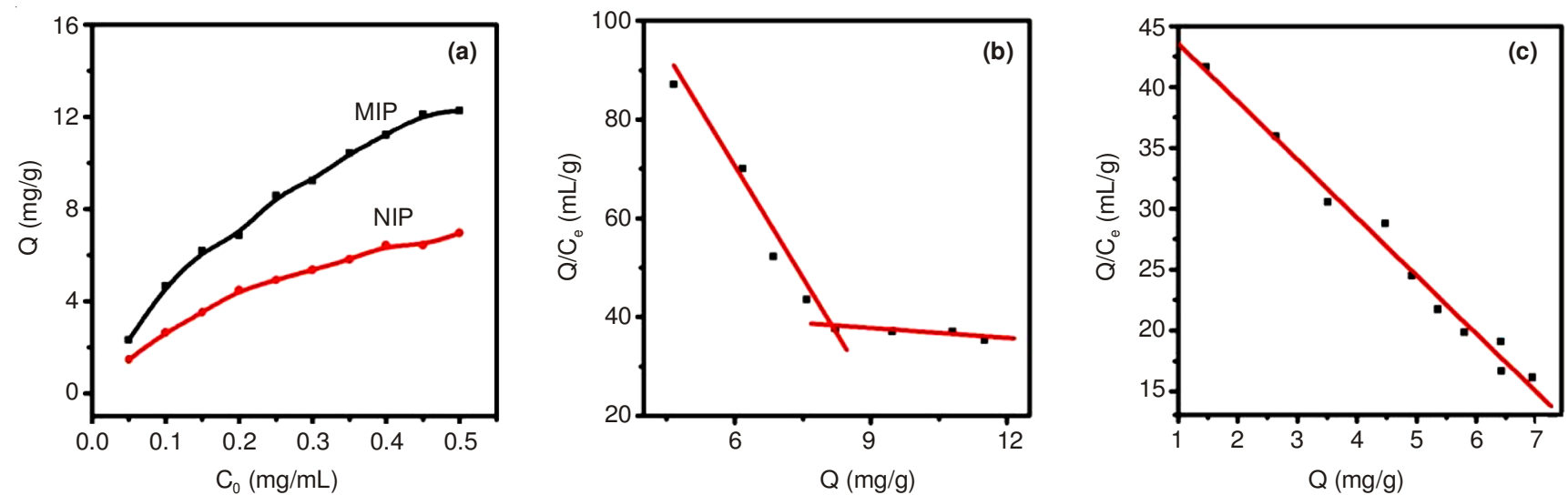

Fig. 4. Binding isotherms (a) and scatchard plot analysis of the binding of chlor-tetracycline hydrochloride (CTC) onto the MIMM (b) and the nonimprinted magnetic microsphere (NIM) (c)

hydrochloride onto molecularly imprinted magnetic microsphere and non-imprinted magnetic microsphere were shown in Fig. 4a. Chlortetracycline adsorption of the molecularly imprinted magnetic microsphere and non-imprinted magnetic microsphere increased with the increase of the initial concentrations. It is obvious that the molecularly imprinted magnetic microsphere has a higher adsorption capacity than the nonimprinted magnetic microsphere.

In general, the Scatchard plot is used for the evaluation of adsorption parameters. Furthermore, the Scatchard plot can indicate how many kinds of binding sites exist in the molecularly imprinted magnetic microsphere. The average binding data of triplicate independent results can be linearly transformed according to the Scatchard equation $\left(\mathrm{Q} / \mathrm{C}_{\mathrm{e}}=\left(\mathrm{Q}_{\max }-\mathrm{Q}\right) /\right.$ $K_{d}$ ). The results indicated that there were two different binding sites in the molecularly imprinted magnetic microsphere (Fig. 4b) and only one kind of binding site in the non-imprinted magnetic microsphere (Fig. 4c). In Fig. 4b, the fitting liner equation for the molecularly imprinted magnetic microsphere: $\mathrm{Q} / \mathrm{C}_{\mathrm{e}}=155.78-14.57 \mathrm{Q}$ and $\mathrm{Q} / \mathrm{C}_{\mathrm{e}}=42.79-0.6 \mathrm{Q}$, the equilibrium dissociation constants $\left(\mathrm{K}_{\mathrm{d}}\right)$ of $6.86 \times 10^{-2} \mathrm{mg} \mathrm{mL}^{-1}$ and 1.67 $\mathrm{mg} \mathrm{mL}^{-1}$ and the apparent maximum binding capacities $\left(\mathrm{Q}_{\max }\right)$ of $10.69 \mathrm{mg} / \mathrm{g}$ and $71.46 \mathrm{mg} / \mathrm{g}$ could be calculated from the slope and the intercept of the linear equation. Similarly, $\mathrm{K}_{\mathrm{d}}$ $(0.21 \mathrm{mg} / \mathrm{mL})$ and $\mathrm{Q}_{\max }(10.16 \mathrm{mg} / \mathrm{g})$ were calculated from the fitting liner equation $\left(\mathrm{Q} / \mathrm{C}_{\mathrm{e}}=48.34-4.76 \mathrm{Q}\right)$ for the nonimprinted magnetic microsphere (Fig. 4c). It indicated that the specific affinity and the binding capacity of the molecularly imprinted magnetic microspheres were significantly larger in comparison with the non-imprinted magnetic microsphere.

Optimization of magnetic dispersion extraction conditions: In order to enhance extraction efficiency, the amount of molecularly imprinted magnetic microspheres must be large enough to extract the analytes as completely as possible. The amounts of the molecularly imprinted magnetic microspheres ranged from 10 to $100 \mathrm{mg}$ in $5 \mathrm{~mL}$ standard solution, the recoveries from 76.5-95.7 \% were obtained for the chlortetracycline hydrochloride. The results manifested that $50 \mathrm{mg}$ of the molecularly imprinted magnetic microspheres were enough for the extraction. As can be seen from Fig. 5, when extraction time for $20 \mathrm{~min}$, the recovery reached $93 \%$. If increased extraction time, the recoveries had no obvious change.

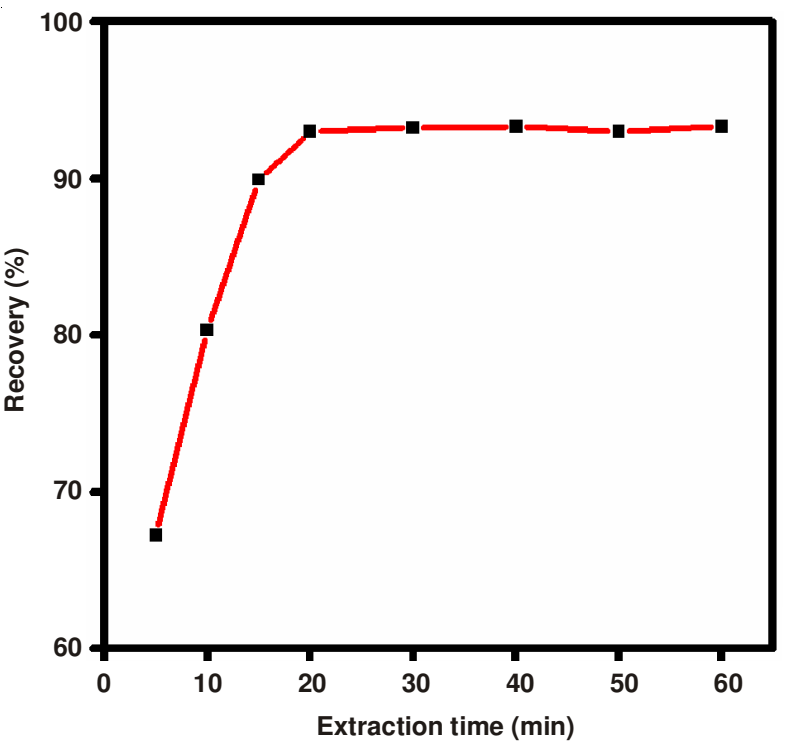

Fig. 5. Effect of extraction time on extraction efficiency

According to a previous study ${ }^{12}$, citrate buffer as extraction solution was applied in the present study. Effect of $\mathrm{pH}$ in magnetic dispersion extraction on extraction efficiency was performed from 2 to 6 . As the Fig. 6 indicated, the results showed that a $0.1 \mathrm{~mol} / \mathrm{L}$ of citrate buffer $(\mathrm{pH} 4)$ afforded the best effect and the best recovery $(90.8 \%)$ was obtained. In order to enhance the selectivity of the molecularly imprinted magnetic microspheres and decrease the matrix interference, the washing conditions were optimized. A washing solution with moderate elution strength was used to damage the nonspecific interactions and to let the target analyte be retained by specific interactions. Several different polar solvent such as water, methanol, acetonitrile and toluene were investigated as washing solvents and different proportions and volumes of methanol and toluene were also investigated. The better result was obtained using $2 \mathrm{~mL}$ of methanol-toluene $(1: 19, \mathrm{v} / \mathrm{v})$ as the washing solution.

The eluting step was optimized based on the principle of elution that the analytes could be eluted completely by a small volume of strong solvent, while the impurities could not be eluted as much as possible. A series of elution solvents including water, methanol and acetonitrile with acetic acid in different proportions were used to optimize the eluting conditions. It 


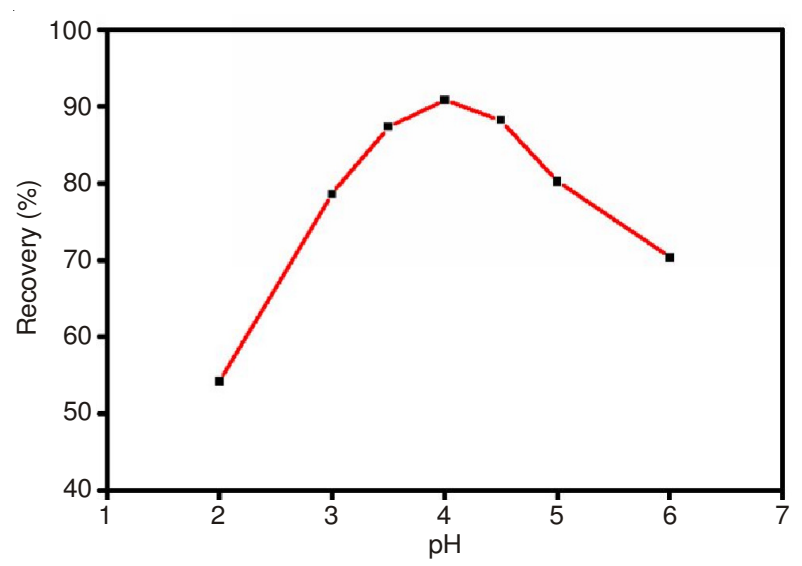

Fig. 6. Effect of $\mathrm{pH}$ in MDE on extraction efficiency

was found acidified methanol solution was sufficient to achieve satisfactory result with the tetracyclines recoveries in the range of 76.7-95.1\%. The better recovery was obtained by using $2 \mathrm{~mL}$ of $0.5 \%$ acetic acid methanol solution as the optimized eluting solution in the following work.

Determination of tetracyclines in real samples by MIMM-MDE-HPLC: The feasibility and applicability of magnetic dispersion extraction were evaluated by extraction of trace tetracyclines from the milk samples at MRL levels
$(0.1 \mathrm{mg} / \mathrm{kg})$ in FDA, EU and China's Ministry of Agriculture. The analytical results were shown in Fig. 7. Under the optimized condition, the average recoveries of four tetracycline antibiotics spiked milk at $0.1,0.2$ and $0.5 \mathrm{mg} / \mathrm{kg}$ were in the range of 76.4-95.84\% with relative standard deviations (RSDs) of 2.72-6.81\% (Table-1). The limits of detection (LOD, S/N $=3$ ) and the limits of quantitation (LOQ, S/N = 10) of the proposed method were respectively 5.71 and $19.02 \mu \mathrm{g} / \mathrm{kg}$ for oxytetracycline hydrochloride, 7.84 and $26.12 \mu / \mathrm{kg}$ for tetracycline, 6.62 and $22.07 \mu \mathrm{g} / \mathrm{kg}$ for chlortetracycline hydrochloride, 11.18 and $37.28 \mu \mathrm{g} / \mathrm{kg}$ for doxycycline hydrochloride. As Fig. $7 \mathrm{~b}$ can be observed, a good clean-up result was obtained in comparison with Fig. 7a. As it can be observed in the chromatograms, the noises in Fig. $7 \mathrm{~b}$ and $7 \mathrm{c}$ were much less than those in Fig. 7a, which is helpful to improve the selectivity of food analysis.

\section{Conclusion}

A novel molecularly imprinted magnetic microsphere was prepared for magnetic dispersion extraction of tetracycline antibiotics from milk simples. We have demonstrated that the magnetic dispersion extraction makes breakthrough over the traditional extraction methods. So, the magnetic dispersion extraction is promising as a general strategy for clean-up and pre-concentration.
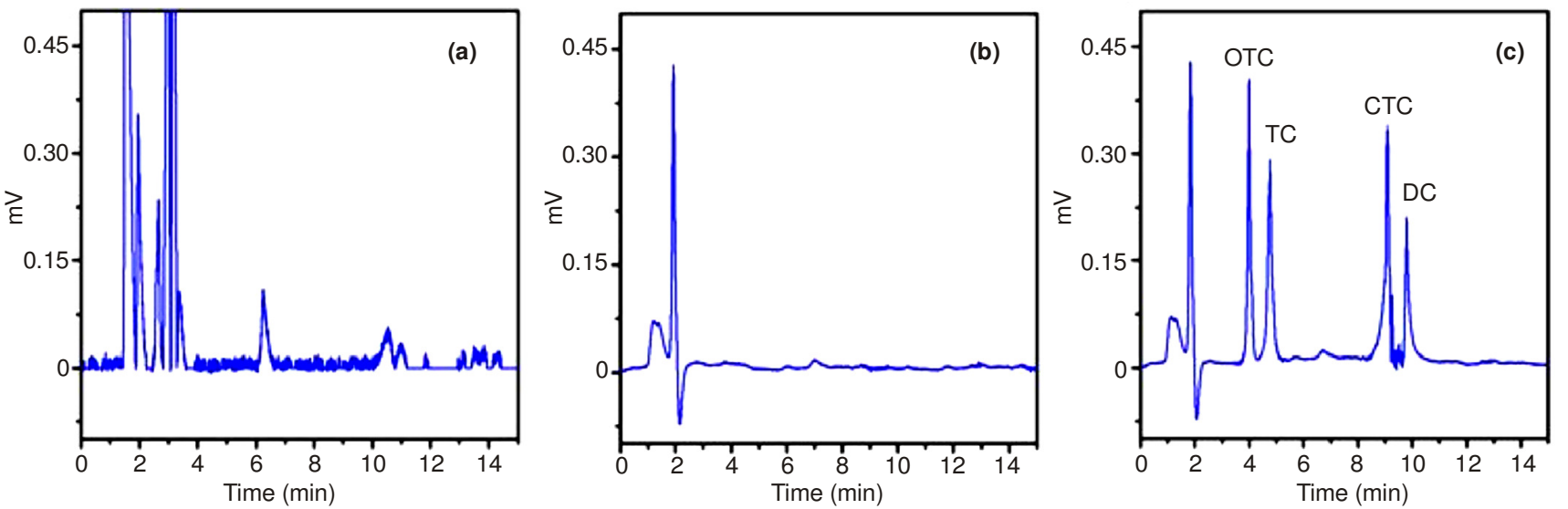

Fig. 7. Chromatograms of oxytetracycline hydro-chloride (OTC), tetracycline hydrochloride (TC), chlortetracycline hydrochloride (CTC) and doxycycline hydrochloride (DC) were obtained from (a) Blank milk, (b) Blank milk after MISPE and (c) Milk sample spiked with concentration (0.1 mg/kg). Mobile phase: methanol/acetonitrile/10 $\mathrm{mM}$ oxalic acid solution (5:25:70, v/v); flow rate: $1 \mathrm{~mL} / \mathrm{min}$

TABLE-1

AVERAGE RECOVERIES (R), RELATIVE STANDARD DEVIATIONS (RSDS, N = 3), LIMIT OF DETECTION (LOD) AND LIMIT OF QUANTITATION (LOQ) OF FOUR TETRACYCLINES WERE OBTAINED AFTER MIMM OF THE SPIKED MILK SAMPLES ( $\mathrm{n}=5$ )

\begin{tabular}{|c|c|c|c|c|c|c|}
\hline Analyte & Spiked level $(\mathrm{mg} / \mathrm{kg})$ & Detected $(\mathrm{mg} / \mathrm{kg})$ & $\mathrm{R}(\%)$ & $\operatorname{RSD}(\%)$ & $\operatorname{LOD}^{\mathrm{a}}(\mu \mathrm{g} / \mathrm{kg})$ & $\mathrm{LOQ}^{\mathrm{b}}(\mu \mathrm{g} / \mathrm{kg})$ \\
\hline \multirow{3}{*}{$\begin{array}{l}\text { Oxytetracycline } \\
\text { hydro-chloride }\end{array}$} & 0.1 & 0.0822 & 82.20 & 4.32 & \multirow{3}{*}{5.71} & \multirow{3}{*}{19.02} \\
\hline & 0.5 & 0.4631 & 92.62 & 3.74 & & \\
\hline & 1.0 & 0.9453 & 94.53 & 5.23 & & \\
\hline \multirow{3}{*}{$\begin{array}{l}\text { Tetracycline } \\
\text { hydrochloride }\end{array}$} & 0.1 & 0.0818 & 81.80 & 3.41 & \multirow{3}{*}{7.84} & \multirow{3}{*}{26.12} \\
\hline & 0.5 & 0.4592 & 91.84 & 4.90 & & \\
\hline & 1.0 & 0.9034 & 90.34 & 2.72 & & \\
\hline \multirow{3}{*}{$\begin{array}{l}\text { Chlortetracycline } \\
\text { hydrochloride }\end{array}$} & 0.1 & 0.0764 & 76.40 & 6.81 & \multirow{3}{*}{6.62} & \multirow{3}{*}{22.07} \\
\hline & 0.5 & 0.4393 & 87.86 & 5.12 & & \\
\hline & 1.0 & 0.8975 & 89.75 & 4.91 & & \\
\hline \multirow{3}{*}{$\begin{array}{l}\text { Doxycycline } \\
\text { hydrochloride }\end{array}$} & 0.1 & 0.0796 & 79.60 & 3.92 & \multirow{3}{*}{11.18} & \multirow{3}{*}{37.28} \\
\hline & 0.5 & 0.4612 & 92.24 & 3.14 & & \\
\hline & 1.0 & 0.9584 & 95.84 & 2.84 & & \\
\hline
\end{tabular}

${ }^{a}$ LOD calculated as 3 times the signal-to-noise ratio; ${ }^{b}$ LOQ calculated as 10 times the signal-to-noise ratio. 


\section{ACKNOWLEDGEMENTS}

This research was supported by the National Natural Science Foundation of China (No. 21275053) and the Natural Science Foundation of Hebei Province (No. B2011201081).

\section{REFERENCES}

1. R.J. Ansell and K. Mosbach, Analyst, 123, 1611 (1998).

2. Y. Zhang, R.J. Liu, Y.L. Hu and G.K. Li, Anal. Chem., 81, 967 (2009).

3. S.L. Lu, G.X. Cheng, H.G. Zhang and X.S. Pang, J. Appl. Polym. Sci., 99, 3241 (2006).

4. C.J. Tan, H.G. Chua, K.H. Ker and Y.W. Tong, Anal. Chem., 80, 683 (2008).

5. X.W. Kan, Z.R. Geng, Y. Zhao, Z.L. Wang and J.J. Zhu, Nanotechnology, 20, 165601 (2009).
6. L. Li, X.W. He, L.X. Chen and Y.K. Zhang, Chem. Asian J., 4, 286 (2009).

7. C. Gonzato, M. Courty, P. Pasetto and K. Haupt, Adv. Funct. Mater., 21, 3947 (2011).

8. Q.Q. Gai, F. Qu, Z.J. Liu, R.J. Dai and Y.K. Zhang, J. Chromatogr. A, 1217, 5035 (2010).

9. Y.L. Liu, Y.Y. Huang, J.Z. Liu, W.Z. Wang, G.Q. Liu and R. Zhao, J. Chromatogr. A, 1246, 15 (2012).

10. Standardization Administration of China, GB/T 22990-2008, Determination of Oxytetracycline, Tetracycline, Chlortetracycline, Doxycycline Residues in Milk and Milk Powder-HPLC-UV Method.

11. B. Sellergren, M. Lepistoe and K. Mosbach, J. Am. Chem. Soc., 110, 5853 (1988).

12. Y.K. Lv, L.M. Wang, L. Yang, C.X. Zhao and H.W. Sun, J. Chromatogr. A, 1227, 48 (2012). 